\title{
Os Conflitos de Terras em Territórios Indígenas de Rondônia a partir da Expansão do Capital Globalizado
}

\author{
Land Conflicts in Indigenous Territories in Rondônia due to the Expansion of \\ Globalized Capital
}

\section{Conflictos Territoriales en los Territorios Indígenas de Rondônia por la Expansíon del Capital Globalizado}

\author{
Carlandio Alves da Silva ${ }^{1}$ \\ https://orcid.org/0000-0001-6927-3232 \\ Onelia Carmem Rossetto ${ }^{2}$ \\ https://orcid.org/0000-0003-1440-9125
}

\begin{abstract}
RESUMO: Os processos de espacialização do capital globalizado e de ordenamento territorial resultaram em múltiplos conflitos. Diante da problemática, este texto tem como objetivo esclarecer e dar entendimento dos conflitos que ocorreram durante o processo de ordenamento territorial no estado de Rondônia, sendo este o espaço onde se buscaria desenvolvimento aliado à proteção do ambiente, das etnias e das populações tradicionais. Como pressuposto metodológico, optou-se pela pesquisa bibliográfica qualitativa e fontes secundárias de dados. Concluiu-se que o Estado como organizador e gestor desse espaço, algumas vezes, trouxe malefícios para os grupos indígenas, pois ocorreram poucos diálogos com esses povos, a não ser para imposição da cultura. A necessidade de proteção das fronteiras, ou desenvolvimento econômico, resultou na extinção de algumas etnias e a debilidade de outras que quase chegaram a ser dizimadas. O desenvolvimento feito pelo Estado foi baseado no conflito de interesses de grupos migrantes que necessitavam de terras para trabalho e grupos indígenas que necessitam do meio ambiente para sobreviver.
\end{abstract}

PALAVRAS-CHAVE: Políticas Públicas. Projetos. Etnias. Colonização.

ABSTRACT: The processes of globalized capital spatialization and territorial ordering resulted in multiple conflicts. In face of such problems, this text aims to clarify and give an understanding about conflicts that occur during the process of territorial planning for Rondônia state, this being the space where development would be sought together with the protection of the environment, ethnic groups and traditional populations. As methodological assumption, bibliographical qualitative research and secondary data sources were chosen. It was concluded that the State as the organizer and manager

\footnotetext{
${ }^{1}$ Mestrando na Universidade Federal de Mato Grosso - Programa de Pós-Graduação em Geografia. E-mail: oidnalrac@gmail.com.

${ }^{2}$ Doutora em Desenvolvimento Sustentável pela Universidade de Brasília. Pesquisadora Associada ao Programa de Pós-Graduação em Geografia - Universidade Federal de Mato Grosso/UFMT. E-mail: carmemrossetto@gmail.com.
} 
of this space, has always brought harm to indigenous groups, since there were few dialogues with these peoples, except for the imposition of culture. The need for border protection, or economic development, has resulted in the extinction of some ethnic groups and the precariousness of others that have almost been decimated. State development was based on conflict of interest, migrant groups that needed land for work and indigenous groups that need the environment to survive.

KEYWORDS: Public Policies. Projects. Ethnicities. Colonization.

RESUMEN: Los procesos de especialización del capital globalizado y ordenamiento territorial resultó en múltiples conflictos. Ante esta problemática, este texto pretende esclarecer y dar una comprensión de los conflictos ocurridos durante el proceso de ordenamiento territorial en el estado de Rondônia, siendo este el espacio, donde se buscaría el desarrollo conjuntamente con la protección del medio ambiente, etnias y poblaciones tradicionales. Como supuesta metodología se eligió una búsqueda bibliográfica cualitativa de fuentes y de datos secundarios. Se concluyó que el Estado es el organizador y gestor de este espacio, y que siempre ha traído daño a los grupos indígenas, ya que no existe ningún tipo de diálogo con estos pueblos, salvo para la imposición de la cultura. La necesidad de protección fronteriza, y desarrollo económico, ha provocado la extinción de algunos grupos étnicos y la precariedad de otros que casi han desaparecido. El desarrollo que llevó a cabo el Estado se basó en el conflicto de intereses, de grupos de migrantes que necesitaban tierras para trabajar y de grupos indígenas que necesitan del medio ambiente para sobrevivir.

PALABRAS CLAVE: Políticas Públicas. Proyectos. Etnias. Colonización.

\section{INTRODUÇÃO}

Este texto tem como fundamento e objetivo esclarecer e dar entendimento sobre os conflitos que ocorreram durante o processo de ordenamento territorial no estado de Rondônia e ainda se fazem presentes na unidade federativa, que deveria ser, segundo os projetos de colonização e o zoneamento sócio-econômico-ecológico (ZSEE), o espaço de desenvolvimento aliado à proteção do ambiente, das etnias e das populações tradicionais. Para evidenciar esse cenário, da problemática da espacialização do capital influenciando os impactos às etnias, se fez necessário a abertura de um debate sobre as transformações geográficas que ocorreram no espaço ao longo do tempo.

Os períodos anteriores ao ZSEE, em que a produção da borracha passou a coincidir com outras três atividades incentivadoras da vinda de migrantes para região Amazônica, segundo Moser (2006), trouxeram funções econômicas para Rondônia. Isso obrigou o Estado a um melhor aparelhamento com estratégias apoiadas pelo governo brasileiro na construção da Estrada de Ferro Madeira Mamoré e instalação das linhas telegráficas. Estas últimas ocuparam as áreas conhecidas como vazios demográficos.

O Estado brasileiro utilizou-se da unidade federativa para inserir o projeto de uso e ocupação do solo, direcionado a utilização de maior área possível em conformidade com a sustentabilidade requerida pelo Banco Mundial. Em conjunto com os projetos e programas 
ocorreu também a abertura da BR 364, que foi um dos eixos para a transformação territorial das terras indígenas no estado (figura 1).

Figura 1: Mapa da espacialização das terras indígenas em Rondônia

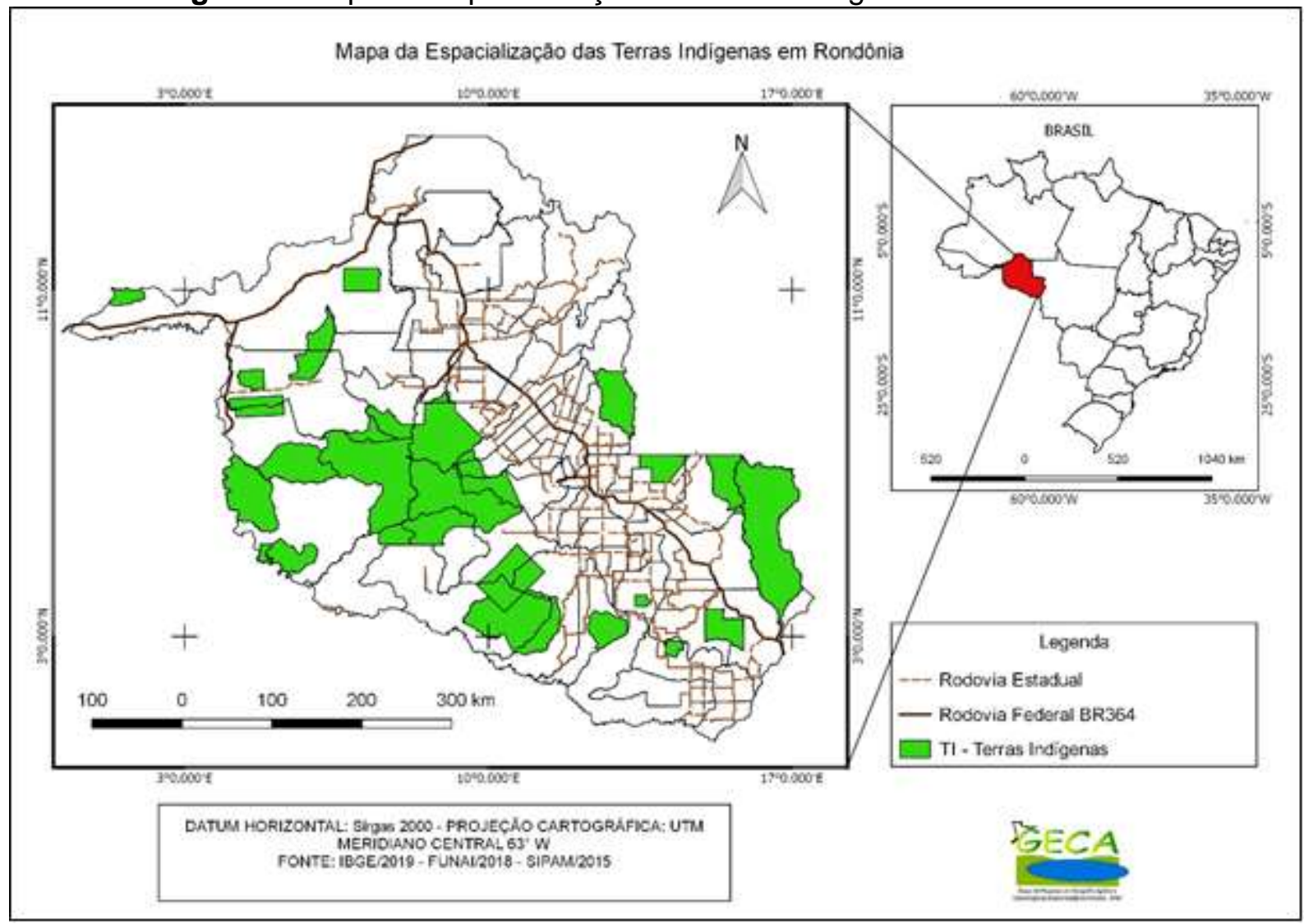

Fonte: BRASIL, 2015; BRASIL, 2018; IBGE, 2019.

Em 1943 a área física do estado de Rondônia foi originariamente desmembrada de Mato Grosso e Amazonas, sendo criado o território do Guaporé, o qual somente em 1981 passou à categoria de estado, localizado na região norte, e com seus limites estabelecidos junto às unidades federativas do Acre, Amazonas e Mato Grosso. Possui 23 terras indígenas demarcadas, agregadoras de 23 etnias. Deve-se levar em conta que no mapa não aparece cinco áreas com povos indígenas, pois estão em fase de estudo e somente após todo o processo é que devem constar como terras indígenas demarcadas (BRASIL, 2020).

As Terras Indígenas (Tls) de Rondônia, conforme pode ser percebido na figura 1, estão diretamente interligadas com a criação da BR 364. Segundo Silva (2012, p. 11), "[...] a maioria das Unidades de Conservação (UCs) e Tis [...]" foram criadas no período do Plano Agropecuário e Florestal de Rondônia (PLANAFLORO). No entanto, "[...] o componente indígena recebeu o menor nível de investimento quando comparado aos demais".

Após pressões de entidades civis não governamentais, as Terras Indígenas no Brasil foram demarcadas com o intuito de proteção às etnias, pois há a necessidade de 
permanência em suas áreas para que seu modo de vida seja perpetuado por seus descendentes. De acordo com a Constituição Federal de 1988, o capítulo VIII dispõe que:

\begin{abstract}
Art. 231. São reconhecidos aos índios sua organização social, costumes, línguas, crenças e tradições, e os direitos originários sobre as terras que tradicionalmente ocupam, competindo à União demarcá-las, proteger e fazer respeitar todos os seus bens. $\S 1^{\circ}$ São terras tradicionalmente ocupadas pelos índios as por eles habitadas em caráter permanente, as utilizadas para suas atividades produtivas, as imprescindíveis à preservação dos recursos ambientais necessários a seu bem-estar e as necessárias a sua reprodução física e cultural, segundo seus usos, costumes e tradições. $\S$ $2^{\circ}$ As terras tradicionalmente ocupadas pelos índios destinam-se a sua posse permanente, cabendo-Ihes o usufruto exclusivo das riquezas do solo, dos rios e dos lagos nelas existentes. $\S 3^{\circ} \mathrm{O}$ aproveitamento dos recursos hídricos, incluídos os potenciais energéticos, a pesquisa e a lavra das riquezas minerais em terras indígenas só podem ser efetivados com autorização do Congresso Nacional, ouvidas as comunidades afetadas, ficando-Ihes assegurada participação nos resultados da lavra, na forma da lei. $\S 4^{\circ}$ As terras de que trata este artigo são inalienáveis e indisponíveis, e os direitos sobre elas, imprescritíveis (BRASIL, 1988, p. 133).
\end{abstract}

Com a necessidade de legitimar a posse e uso da terra pelos povos indígenas a Constituição Federal de 1988 elenca os direitos. No entanto, a inobservância e a desobediência colocam a vida das etnias em constante risco. Mesmo que suas áreas tradicionalmente ocupadas sejam utilizadas para atividades produtivas imprescindíveis à preservação dos recursos ambientais necessários ao seu bem-estar e para reprodução física e cultural, segundo seus costumes e tradições, e que sofram constante ataques e depredação, há por parte do indígena a resistência e defesa, o que em Rondônia durante todo o período de colonização até a atualidade resulta em constantes mortes e perdas de seu território.

\title{
PROCEDIMENTOS METODOLÓGICOS
}

Para conhecer os fenômenos humanos e poder descrevê-los, tal qual a forma como ocorreram e como se deu a espacialização dos conflitos socio-territoriais e suas variações em Rondônia, subsidiou-se em autores como Borges (2012); Costa Silva (2010); Costa Silva e Dandolini (2018); Coy (1987, 1988); Moser (2006); Ott (2002), e Estes pesquisaram a Amazônia com foco principal para ocupação em Rondônia, buscando compreender as frentes pioneiras, a formação do capital social, o desenvolvimento sustentável, juntamente com os projetos e políticas territoriais para aceleração do crescimento econômico que fundamentaram as transformações no espaço rondoniano ao longo do tempo. Em conjunto com esses autores, pensou-se o espaço e as suas tecnificações a partir da visão de Porto-Gonçalves (2011) e Santos (1997, 2004, 2012), os 
quais atuaram para compreensão da forma globalizada do capital manifestado na economia local.

O embasamento metodológico seguiu a técnica utilizada para produção de textos acadêmicos, utilizando Demo (1992) e Köche (2005). Para explicar os passos para efetivação de um texto científico, com critérios específicos, foi escolhido o viés de pesquisa bibliográfica qualitativa com tipologia descritiva e explicativa. Os dados são de fontes secundárias, as quais, segundo Castro e Silva (2020), são obtidas em documentos físicos ou eletrônicos, tais como jornais, periódicos, revistas científicas, livros, artigos, monografias, dissertações e teses analisados sob a luz do método marxista.

Com o método do materialismo histórico dialético se concebeu um olhar geográfico da realidade. Sobre as questões referentes a diferenças sociais, os conflitos resultantes do processo de exclusão, propiciados pelo capital, foram estudados e evidenciados para compreensão da sociedade. Nesse sentido, autores como Harvey (1992); Hobsbawm (2006); Lefebvre (2017); Martins (2019); Politzer (1975) foram imprescindíveis.

No materialismo histórico dialético há uma concepção de natureza idealista, e ocorre o predomínio das ideias colocadas em relação à matéria. No entanto, sua análise não admite a hipótese de uma harmonia espontânea, pois reconhece a existência das contradições tanto no homem como na sociedade humana. Dentro dessa lógica, Politzer (1975) indica que o homem se define pelo conhecimento e pelas ciências e suas descobertas.

As ciências são mediadas pelo homem, que tem uma relação fundamental com a natureza através dos seus atos e pensamentos. Mas no centro de suas preocupações está o homem. Nesse sentido, a concepção marxista elaborada a partir dos elementos distintos encontrados na ciência e na filosofia se funde para conceber amplitude nas análises sobre a sociedade, tendo em sua percepção de mundo uma amplitude tracejada pela existência humana e suas contradições, esta denominada de materialismo histórico dialético. Lefebvre (2017) esclarece sobre como são sintetizados e unificados os elementos materialismo e dialética, estes separados e isolados na ciência e na filosofia de seu tempo sobre a alcunha de materialismo filosófico. Estes elementos, no qual a ciência já avançava sobre a natureza, e a ciência esboçada a partir da realidade humana, a dialética de Hegel, fundam a teoria das contradições. Essas contradições podem ser observadas para atender aos processos e mecanismos legais para as espacializações que se deram ao longo do tempo pelo desenvolvimento econômico.

O desenvolvimento econômico não pode ser visto simplesmente como "crescimento econômico" e muito menos decompor-se numa variedade de fatores isolados tais como produtividade ou taxa de acumulação de capital, como fazem alguns vulgares economistas modernos, argumentando que o 
crescimento se dá quando, por exemplo, mais do que $5 \%$ da renda nacional são investidos. Este tipo de crescimento não pode ser discutido, a não ser em termos de épocas históricas determinadas e estruturas sociais particulares (HOBSBAWM, 2006, p. 20).

Analisar o desenvolvimento econômico no olhar marxista é interpretar as contradições que são propagadas, pois o entendimento da noção de espaço está atrelado à concepção dos sistemas de tempo, tais como os dos conflitos socioterritoriais indígenas produzidos pelo capital globalizado nos programas para Rondônia. Nesse caso, a análise do espaço é referendada por meio dos fatos históricos em suas escalas, local, regional, nacional e global. Segundo Santos (1997), a dinâmica de um sistema temporal causa sempre marcas ou rastros, pois cada sistema temporal pode deixar na porção do espaço examinado sua essência, por essas repercussões temporais serem duradouras e sobrepondo-se uma à outra, com exceção de espaços inexplorados, que a modernização de origens externas atinge ainda na forma primitiva, logo:

O espaço geográfico é a natureza modificada pelo homem através do seu trabalho. A concepção de uma natureza natural, onde o homem não existisse ou não fora o seu centro, cede lugar à ideia de uma construção permanente da natureza artificial ou social, sinônimo de espaço humano (SANTOS, 2004, p. 150).

Nesse sentido, os espaços agrários em Rondônia, atualmente, são impactados com as ações humanas que deixam visíveis as temporalidades e processos capitalistas que as populações tradicionais vivenciam. E são envolvidos por políticas cogitadas fora da Amazônia. Ainda assim, muitos grupos indígenas resistiram aos extrativistas seringueiros, garimpeiros, projetos de colonização e de agronegócio. De acordo com Dollfus (1991), a partir das evidências do visível, pode-se mensurar o que foi deixado por gerações passadas e a que velocidade os avanços ocorreram constituindo as estruturas operantes sobre 0 espaço. Logo, as marcas deixadas pelos projetos de colonização em Rondônia devem ser atribuídas às políticas públicas dos não índios que produzem novas espacialidades para os indígenas. Essas, intrinsecamente ligadas às forças produtivas permeadas de contradições e à luta do homem versus natureza como primeiro plano. Lefebvre (2017) salienta que a economia capitalista requer uma análise particular por ser influenciadora na política.

Harvey (1992) considera que o apoderamento do espaço expressa a feição de como as vigorosas corporações ou grupos controlam sua estruturação e produção por meio da legalidade ou extra legalidade com o intuito de executar o máximo de controle, independente da forma que o espaço é apropriado por eles ou por outros. No caso de Rondônia, as dinâmicas territoriais no âmbito rural foram movidas com particularidades na colonização, migração e distribuição de terras como uma fronteira que: 
[...] se comporta como um campo de forças, espaço onde os projetos políticos dos múltiplos agentes territoriais podem ou não se territorializar. Consiste num campo de forças aberto, ao mesmo tempo, virtual e histórico, movimentado pelos projetos dos diversos agentes territoriais que imprime na luta política e no território suas visões e ações para com essa Região (COSTA SILVA; DANDOLINI, 2018, p. 6).

Com isso, a ocupação das fronteiras agrícolas revela a espacialização do capital impactando as terras indígenas em Rondônia, principalmente por fatores econômicos. Martins (2019) esclarece que a fronteira agrícola nesse período proporcionou grandes conjunturas de conflitos das frentes de expansão e frentes pioneiras. Portanto, fica evidente que os espaços sociais são frutos das relações entre pessoas que, segundo Fernandes (2005, p. 274) passa a ser um espaço fragmentado, onde:

As relações sociais são predominantemente produtoras de espaços divididos, singulares, dicotomizados, fracionados, portanto, também conflitivos. A produção de fragmentos ou frações de espaços é resultado de intencionalidades das relações sociais, que determinam as leituras e ações propositivas que projetam a totalidade como parte, ou seja, o espaço em sua qualidade completiva é apresentado somente como uma fração ou um fragmento.

Essas intencionalidades das fragmentações sociais transverte o espaço geográfico, alterando a paisagem e construindo territórios, buscando atingir seus desígnios, criando espaços políticos e espacialidades, o que resulta, segundo Fernandes (2005, p. 279), em ações dicotômicas, pois, "[...] a construção de um tipo de território significa, quase sempre, a destruição de um outro tipo de território" sendo contínuo o processo de territorialização, desterritorialização e re-territorialização, quase sempre imposta por quem detém o poder, limitando áreas e impondo leis.

A inserção política externa em terras de Rondônia foi discutida neste texto, pois tanto os limites e até mesmo alguns toponímios tiveram influência de fora, como é o caso da demarcação dos limites e do nome do rio Roosevelt, após a expedição realizada pelo Marechal Rondon em 1914 (figura 2), que teve a presença de pesquisadores e do expresidente norte americano Teodore Roosevelt. Desta maneira fica claro, quem detém o poder demarca e impõe limites, ficando caracterizado na dinâmica da formação do estado rondoniense.

Já na questão indígena em Rondônia, o movimento do capital especializou, influenciou as políticas e os direitos indígenas. A localidade dos grupos originários, segundo Santos (2019), não diz respeito somente a dimensão material como espaço de reprodução cultural e física. É local de lembrança dos seus antepassados que ali viveram, estando presente na memória. E, na busca de defenderem seus direitos e conquistas históricas que tencionaram 
esses espaços. Logo, cada vez que as pressões do capital impõem alterações drásticas nesses espaços os resultados geram exclusão e desigualdade.

Figura 2: Demarcação da nascente do rio Roosevelt em Vilhena - 1914

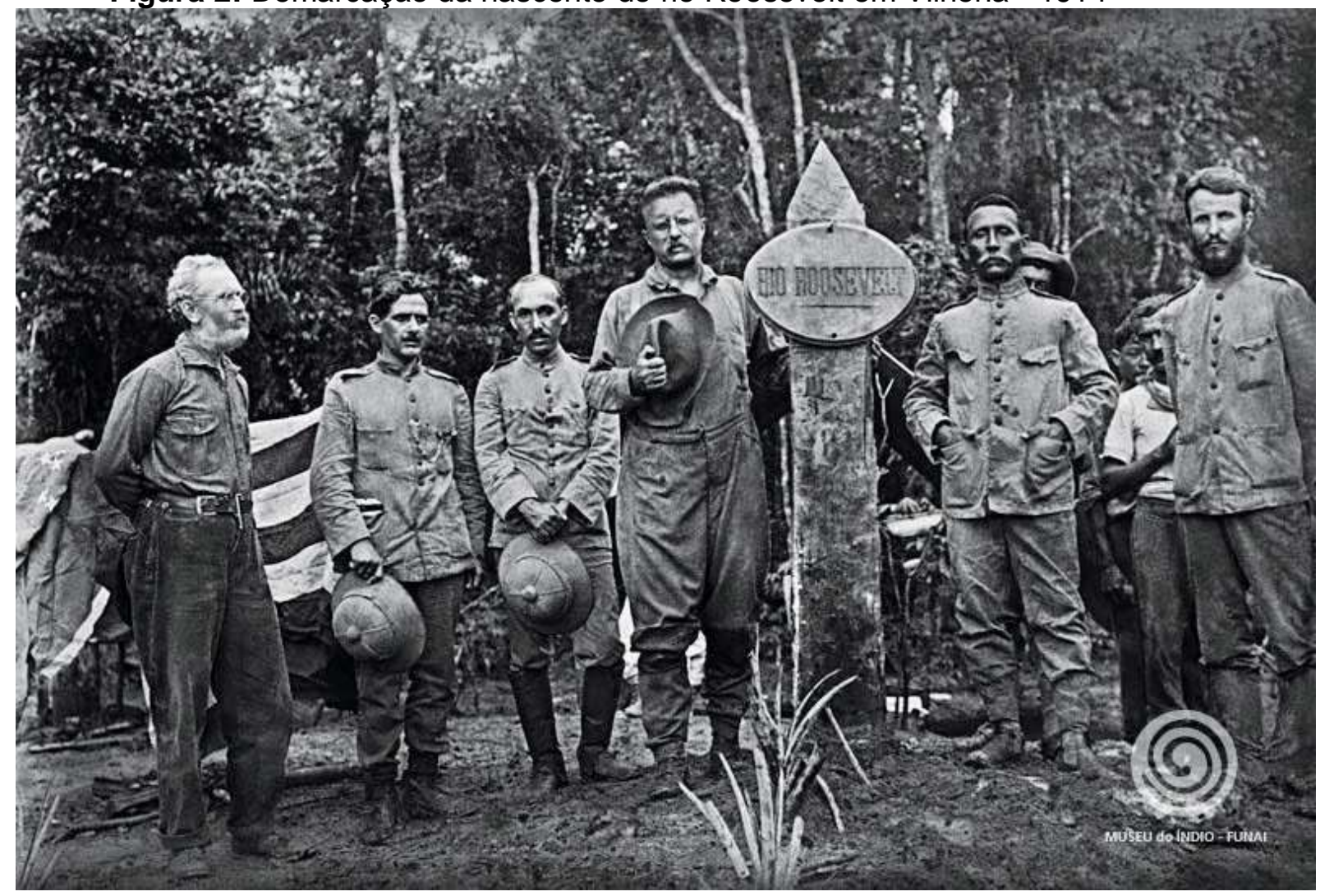

Fonte: BRASIL (2019).

\section{AS DESIGUALDADES, EXPROPRIAÇÃO E MISÉRIA IMPOSTAS PELO CAPITAL NAS ETNIAS DE RONDÔNIA}

A invasão dos europeus na América do Sul, no caso do Brasil pelos portugueses, ocorreu de forma violenta, quando se percebia alguma ameaça que poderia fugir ao seu controle no estabelecimento das capitanias. O governo português agia com o aparato militar contra os indígenas. Segundo Silva (2007, p. 38), "[...] estabeleceu-se um axioma ideológico à época de que índio bom é índio morto". Com essa determinação ainda em voga no país, criou-se o sentimento de que os indígenas necessitavam ser duramente reprimidos. Talvez por isso, no cotidiano, a morte e miséria das etnias não exasperem a sociedade brasileira.

A busca de riquezas e disseminação do cristianismo por meio de missionários marcou uma época de grande violência com os povos indígenas. Segundo De Paula (2008), a conquista do governo português na ocupação do espaço e a busca de mão-de-obra escrava na colônia teve o genocídio indígena utilizado como norma. Ademais, os conflitos étnicos com os não-índios e entre etnias causaram muitas mortes. Com embarcações cada vez 
mais cheias de produtos encontrados no continente americano e levados para a Europa, na volta traziam mais exploradores utilizando-se do nome de Deus para referendar a conquista e pregar o cristianismo às etnias que foram denominados de impuros.

Ao tratar da Amazônia, segundo Silva (2007, p. 36), "[...] a agressividade imposta e deliberada do governo português tinha como objetivo desorganizar as sociedades indígenas". Essas estratégias, forjadas contra a população autóctone, os conduzia à dizimação. Vale lembrar que, no período colonial, tanto espanhóis quanto lusitanos já haviam tido relações com números elevados de indígenas na região. Martins (1971) lembra que a espacialização do domínio português, que se deu mediante alguns conflitos com os espanhóis, era resolvida com a ajuda dos indígenas. No entanto, ao descrever as relações dos missionários e suas intenções religiosas há certo eufemismo, posto que a cooptação dos grupos étnicos não era para liberdade ou educação, e sim para mão-de-obra e serviço de guarda-costas.

Sob o domínio português, parte da Amazônia, em especial as terras que viriam a ser o estado de Rondônia, assistiu à realização de grandes obras como o forte Príncipe da Beira, com sua obra concluída em 1783, uma fortaleza militar cujo objetivo foi garantir a posse das terras às margens do rio Guaporé, fronteira com a Bolívia, devido aos conflitos com a Coroa da Espanha. Segundo Moser (2006), depois de consolidada a presença portuguesa, por não ser mais necessária na função de proteção da fronteira, foi abandonada no período da Primeira República, permanecendo esquecida politicamente num período de 40 anos, sendo ocupado quase por inteiro pela vegetação.

A espacialização do não-índio na Amazônia ficou cada vez mais perceptível e o espaço foi ordenado e construído às custas da escravidão de homens trazidos independentes de sua vontade, para trabalharem e formalizarem os diversos projetos executados em Rondônia. Fatores externos trouxeram para Amazônia o não-índio para dar início ao ciclo econômico da exploração da hevea brasiliensis que favoreceria os detentores do capital durante a economia da borracha.

A seringueira, que foi objeto de cobiça internacional, e a matéria-prima retirada dela, colocou o Brasil durante a Segunda Guerra Mundial em destaque no cenário. Segundo Ott (2002), o inventor americano Charles Goodyear descobriu como fazer para que o produto da hevea brasiliensis tivesse maior elasticidade e resistência ao atrito. A partir de seus conhecimentos foi possível ter a vulcanização da borracha para aplicação industrial, primeiramente utilizada para pneus em bicicletas e posteriormente nos automóveis.

Dessa forma, a vulcanização da borracha foi inserida no mercado globalizado. A população indígena do estado de Rondônia sofreu impacto com os seringais, onde foram delimitados espaços não levando em consideração as etnias que residiam nas proximidades. Com a globalização, o capital na região amazônica causou, e causa ainda 
nos tempos atuais, transformações de forma desigual em concordância com as políticas públicas aplicadas na perspectiva do capital, pois:

A expansão do capitalismo revestia-se de uma aura de missão civilizatória e, dessa forma, absolvia-se o etnocídio e o genocídio que se cometia contra os povos da África, da Ásia e da América Latina, considerados primitivos e atrasados e, portanto, assimilados à natureza-selvagens e bárbaros, estava justificada a sua dominação. A burguesia estaria cumprindo uma missão civilizatória ao destruir povos atrasados (PORTO-GONÇALVES, 2011, p. 13).

Em concordância com Porto Gonçalves (2011); Santos (2014) corrobora ao descrever que a força de trabalho indígena continuou, durante esse período, a participar significativamente da economia amazônica, sendo explorados nas atividades de cargas e descargas dos transportes, na extração vegetal e em outras atividades. O período da borracha estava em destaque na economia mundial, o que deixou a Amazônia e os indígenas como parte desse processo no qual o capital estrangeiro ordenava sua extração. Desta maneira, percebe-se que a economia globalizada tem seu significado e o que pode ser adaptável à produção, ou contribui para o processo de globalização das empresas.

Tudo o que serve à produção globalizada também serve à competitividade
entre as empresas: processos técnicos, informacionais e organizativos,
normas e desregulações, lugares. Tudo o que contribui para construir o
processo de globalização, como ele atualmente se dá, também contribui
para que a relação entre as empresas - e, por extensão, os países, as
sociedades e os homens - esteja fundado numa guerra sem quartel. Como
esta é a lei da produção e da circulação das firmas globais, a cada
momento a maior mais-valia está buscando ultrapassar a si mesma.
Suprema ironia: essa mais-valia tão fugaz não pode ser medida e, ao
mesmo tempo, se torna a principal alavanca, senão o motor unitário, das
ações mais características da economia globalizada (SANTOS, 2012, p.
212).

A produção da borracha em grande escala com finalidades de exportação originou as primeiras vilas em Rondônia, Santo Antônio e Guajará-Mirim. As grandes empresas com intuito de melhorar o escoamento do látex tentaram viabilizar a conexão das duas cidades, partindo do objetivo de construir uma estrada de ferro que ligasse as duas localidades. Segundo Costa Silva (2010), a ferrovia inaugurada em 1912 deveria proporcionar a superação dos trechos que não apresentam condições de navegação devido ao grande número de cachoeiras.

Como outro projeto governamental em conjunto com o capital, a ferrovia Estrada de Ferro Madeira Mamoré ganhou o título de Ferrovia da Morte devido ao número de óbitos causados pelas doenças tropicais. Segundo Ott (2002), as condições de trabalho e vida dos construtores não eram das melhores e, devido a insalubridade que a localidade de Santo 
Antônio demonstrava, o canteiro de obras precisou ser transferido para que se desse a construção da ferrovia, o que ocorreu a sete quilômetros abaixo, onde foi instalada a cidade de Porto Velho.

Praticamente no mesmo período, outra ação governamental para espacialização do capital em Rondônia estava ocorrendo. Trata-se da instalação das linhas telegráficas. Para que fossem implementadas foi formado uma comissão no governo de Affonso Penna (19061909) sob o comando do coronel Cândido Mariano da Silva Rondon (1865-1958). Essa tinha por objetivo integrar pela comunicação o estado do Mato Grosso ao Amazonas e, ambos, ao restante do país. A área do estado de Rondônia está localizada entre os dois estados na parte noroeste do país. Segundo Caser e Sá (2011), os trabalhadores contratados para o empreendimento foram militares, civis e grupos indígenas para os trabalhos mais rudes.

Dessa maneira, a Comissão de Linhas Telegráficas tinha por estratégia proporcionar a possessão consolidada da região amazônica, ignorando os grupos de populações que viviam nesses espaços. O capital, com a ajuda do Estado, avançou sem se preocupar com os autóctones da Amazônia brasileira, o que causou tantos impactos ambientais, mas, para as populações indígenas, foi ainda mais impactante.

As linhas telegráficas serviram como norteadoras para abertura da BR-364 e para os planos de colonização em Rondônia. Segundo Coy (1988), a exploração de cassiterita em Rondônia durante os anos 1950 motivaram a construção da estrada Cuiabá-Porto Velho ligando a Amazônia ocidental ao centro do país, fato que facilitaria nas décadas seguintes a implantação de projetos de ocupação dos chamados espaços vazios (MARTINS, 2019).

O comércio nos anos de 1950 em Rondônia, mais precisamente em Ariquemes, foi movimentado pela exploração do minério, no caso a cassiterita que, segundo Moser (2006), teve um aumento na exploração a partir de 1959 atraindo bastantes trabalhadores para a cidade de Ariquemes devido ao declínio da exploração da borracha. Com as políticas de desenvolvimento e integração da Amazônia, a hecatombe contra os povos indígenas voltou a ocorrer devido ao fluxo migratório mais contínuo, afetando o meio ambiente e fomentando mudanças nas práticas agrícolas, uma metamorfose do modelo extrativista vegetal que mudou a cada dia o meio geográfico natural e técnico. Os migrantes que chegavam priorizavam a derrubada da mata para iniciar suas lavouras garantindo a posse da terra. Assim:

A partir do final da década de sessenta, observa-se um fluxo migratório contínuo e crescente, principalmente de populações camponesas oriundas do Sul, Sudeste e Centro-Oeste brasileiro para essa frente pioneira na Amazônia ocidental. Essas ondas migratórias causaram em Rondônia uma taxa de crescimento populacional de $16 \%$ p.a. na década de setenta, a maior taxa verificada em um estado brasileiro (COY, 1987, p. 253). 
A organização espacial ocorre de maneiras diferentes, tanto de forma dirigida como espontânea, atingindo seringueiros que ficaram na região devido à decadência da borracha nas décadas anteriores. Estes foram empurrados pela frente pioneira. Martins (2019) coloca que o capital em sua expansão territorial passa a ser definido pela frente pioneira, integrando áreas da frente de expansão, deixando os indígenas confinados em seus territórios e ampliando a violência fundamentada no mercado e renda da terra. $O$ conceito de frente pioneira é utilizado por alguns geógrafos, vale lembrar a análise de Borges (2012, p. 61). Nesta, o referido termo "[...] não inclui em si a noção do conflito, da dialética e da relação do contato com o outro, consiste numa visão institucional 'civilizada', em que se excluem as populações locais, tais como os indígenas".

As frentes pioneiras faziam parte das estratégias colocadas pelo Governo Federal no intuito de ocupar as áreas de fronteira da região norte do país durante os anos 1970. Intensificadas no ano de 1981 com a criação do Programa Integrado de Desenvolvimento do Noroeste do Brasil - POLONOROESTE, segundo Costa Silva (2010), este programa forneceu a sustentação para colonização em que as ocorrências dos fluxos migratórios e econômicos priorizaram como área de influência a rodovia BR 364. Para ser posto em prática, o projeto foi financiado pelo Banco Mundial que, devido ao aceleramento da migração, mudaria toda estrutura ambiental, social e cultural. Apesar das propostas em organizar pequenos agricultores provenientes de vários estados brasileiros, sobretudo do centro-sul do país, de acordo com Moser (2006), os migrantes tinham a ideia de que as terras estavam inocupadas e disponíveis para uso, ocupação e trabalho.

O POLONOROESTE tinha como argumento o desenvolvimento e crescimento do país, visando o atendimento básico nas áreas de educação, saúde, proteção da floresta, escoamento da produção e garantia de manutenção das terras e culturas dos grupos indígenas, o que não foi devidamente aplicado.

Julgar Rondônia como fronteira agrícola bem-sucedida, segundo Coy (1988), é incoerente, pois deve-se levar em conta para avaliação os atuais processos de diferenciação social no campo, pois estes são frutos de uma reprodução das estruturas sociais, dos conflitos e mazelas que já ocorriam em outras regiões do país. Nesse sentido, deu-se a continuidade com crescimento exponencial dos conflitos de terra. $O$ que se observou nos empreendimentos ou políticas governamentais dos programas para a região nesse período de organização espacial, é que tinham sua especificidade na externalidade de sua elaboração, pensados sem a participação dos indígenas ou dos povos locais, tais como ribeirinhos e caboclos.

No entanto, as pressões e cobranças também eram externas, já que o POLONOROESTE foi financiado pelo Banco Mundial. As tecnologias de satélites, segundo Ott (2002, p. 122), fotografaram os imensos desmatamentos no espaço de Rondônia, 
evidenciando que "[...] a devastação ambiental foi tão intensa que se tornou necessário buscar amparo em uma nova concepção, um novo modelo que harmonizasse desenvolvimento e proteção ambiental para continuidade ao progresso regional".

Com a decadência do POLONOROESTE, foi elaborado e implementado um novo plano capaz de manter o recurso obtido do Banco Mundial. Denominado de Projeto Agropecuário e Florestal de Rondônia, o PLANAFLORO teve sua dita efetivação com a formulação do ZSEE em 1991, o que conduziu o Banco Mundial a fomentar a Carta Consulta para efetivação do projeto como forma de resgatar o desenvolvimento sustentável em Rondônia. A crítica proposta por Borges (2012) explica que o PLANAFLORO nada mais é que uma roupagem nova do POLONOROESTE, ideologias de ocupações intensas financiadas pelo Banco Mundial com cara de conservacionista. Simplesmente, a mesma prática de degradação e conflitos com as populações tradicionais e os indígenas de maneira velada.

A produção do espaço rondoniano tinha como incentivo a inclusão do Brasil nos mercados para exportação. Todavia, os conflitos também tinham seus destaques com assassinatos, como evidenciado em Moser (2006), situações nas quais morreram produtores, chacinas em aldeias indígenas e até mesmo o assassinato do candidato ao governo, Agenor de Carvalho, em novembro de 1980, que advogava na questão agrária. A vítima era conhecida na área rural e urbana. O PLANAFLORO, segundo Ott (2002), foi criticado pelas organizações não-governamentais antes mesmo de ser iniciada sua execução devido às diversas falhas que foram apontadas desde sua criação. E, logo após sua implementação, em 1993, foi denunciado inúmeras vezes devido ao não-cumprimento do projeto.

Conceitualmente, o zoneamento sócio econômico ecológico serve para organizar o território, tecnificar e especializar as ações de uso da terra, e deve ser indicado o quê e onde plantar, quais áreas são para extrativismo e como pode ser realizada a retirada de minérios do solo, dentre outras utilizações possíveis que o homem pode fazer uso da terra, águas e floresta, conforme legislação vigente. Nesse sentido, Ott (2002) explica que devido a muitas falhas no POLONOROESTE, novos projetos são implantados sem muita eficácia na questão indígena, pois são projetos que fazem parte do jogo político para reeleição, negociados pelo governo do estado, que ao final o governo trata como sucesso:

Ao seu final, o ZSEE tornou-se sinônimo do PLANAFLORO. As publicações oficiais do governo (PLANAFLORO, 2000, RONDÔNIA HOJE, 2000), direcionadas ao público externo, destacavam com ênfase o "sucesso" na execução do zoneamento. Da mesma forma que enfatizavam a criação e demarcação de 51 unidades de conservação (24 reservas extrativistas, 06 parques, 04 reservas biológicas, 04 estações ecológicas, 11 florestas estaduais, 02 florestas nacionais) e de 22 áreas indigenas. Todos os outros 
componentes do PLANAFLORO foram discretamente esquecidos (OTT, 2002, p. 236).

As demarcações de reservas e terras indígenas, segundo Pedlowski, Dale e Matricardi (1999), foram processos muito vagarosos no período do PLANAFLORO. As burocracias do governo federal, juntamente com o governo estadual, em relação à transferências dos direitos, foram lentas. Devido às dificuldades de acordo entre o INCRA, o Instituto de Terras de Rondônia (ITERON) e a Fundação Nacional do Índio (FUNAI), a demora das soluções para os devidos casos resultou em avanço na disputa pela terra em todo o estado de Rondônia. Há indicativos de que o encadeamento da grilagem tenha sido liderado pelos donos de madeireiras, agropecuárias, agricultores e até mesmo pelos sem-terra. Consequentemente, não é surpresa ultimamente haver muito desmatamento em Rondônia em áreas que estariam destinadas a terras indígenas e unidades de conservação.

Em consonância com os autores Hobsbwan (2006); Lefebvre (2017); Porto-Gonçalves (2011); Santos (2012), o capital vem tentando dominar a natureza, travando uma verdadeira guerra à sustentabilidade ambiental e aos grupos étnicos, quilombolas e ribeirinhos, de maneira a procurar soluções para o desenvolvimento econômico. No entanto, esse não é voltado para a população local, de maneira que o espaço natural começa a ser substituído por objetos fabricados, máquinas no meio da selva para o favorecimento de um mercado internacional e globalizado que esquece cada vez mais a população tradicional e as etnias das localidades atingidas pela busca de lucro.

A resistência ou sobrevivência da cultura dos povos indígenas nunca foi fácil, mas enquanto houve áreas florestadas para fugir puderam muitas vezes migrar, pois todas as vezes que houve confronto direto eles sucumbiram. O não-índio detém a tecnologia do capital que o favoreceu e favorece com armas, marketing e doenças que matou e continuam a ceifar a vida de índios até hoje. Estes últimos continuam sofrendo com o dito progresso do país; as aberturas de estradas para auxiliar a colonização trouxe o contato, poluindo a terra habitada pelos indígenas, introduzindo a bebida alcoólica, doenças infecciosas e desmatando a floresta. Ainda assim, muitos povos indígenas sobreviveram, depois de terem seus territórios invadidos, e foram alcançados pelos novos projetos de colonização elaborados pelo Estado.

No século XX, segundo Silva (2007, p. 206), na busca de novas áreas para exploração da borracha os seringueiros passam a exercer o papel de soldado da borracha. Os grupos indígenas "[...] indubitavelmente vulneráveis que lutavam pela preservação de seu território ancestral", eram obrigados pelos "[...] conflitos e para sobreviverem, ir cada vez mais para o interior das florestas". A maneira como os seringalistas ocuparam a região do atual estado de Rondônia não foi harmoniosa e todas as ações hostis que os indígenas aplicavam em defesa do seu território, como forma de contra-ataque, tinham um preço a pagar muito 
maior, pois os donos dos seringais eram cada vez piores, usando de diversos armamentos e maneiras de enganar os indígenas para poder matá-los.

Referente aos projetos de colonização, De Paula (2008) ressalta que os colonos sulistas foram contrariados pela falsa ideia de "espaço vazio". As terras destinadas pelo INCRA, em parte, estavam habitadas secularmente por populações indígenas e por seringueiros desde o final do século XIX, o que gerou diversos conflitos pela posse da terra, exterminando muitos índios. Com isso, entende-se que a abertura da BR-364, o POLONOROESTE, PLANAFLORO e o ZSEE, utilizados por pressões do capital, externo a Rondônia, deixaram explícita uma ocupação conflituosa da terra com pressões devido ao aceleramento do crescimento populacional afetando de forma negativa as etnias do estado.

\section{CONSIDERAÇÕES FINAIS}

A necessidade de proteção das fronteiras, ou desenvolvimento econômico na região, resultou na extinção de algumas etnias e a outras quase chegaram a ser dizimadas. $O$ desenvolvimento feito pelo Estado foi baseado no conflito de interesses de grupos de migrantes que necessitavam das terras para trabalho e grupos indígenas que necessitam do meio ambiente para sobreviver de acordo com seu modo de vida. Rondônia, por todos os processos de ocupação, colonização e conflitos que ocorreram na espacialização ao longo do tempo, com a participação do Estado como organizador e gestor, trouxe malefícios para os grupos indígenas, pois o diálogo com esses povos pouco ocorreu, a não ser para imposição da cultura do não-índio. Além disso, atualmente, no tocante ao poder executivo e às políticas públicas direcionadas à proteção das terras indígenas, as etnias inexistem, deixando ainda mais crítica a situação desses povos.

A abertura da BR-364, na prática, foi a principal ferramenta para deslocamento de pessoas e tecnologias na região, o que ocasionou a proximidade dos não indígenas a diversas etnias, resultando em mortes de diversas formas, tanto por doenças não conhecidas pelos índios, quanto pelos conflitos que geraram genocídios. As demarcações em áreas de preservação e terras indígenas ajudam a defender os seus territórios. No entanto, a precariedade dos órgãos gestores não surte os efeitos esperados com respaldos em outras questões nas quais o Estado não atua de modo eficaz, como a saúde indígena, educação e segurança contra invasores.

\section{REFERÊNCIAS}

BORGES, Luciana Riça Mourão. Políticas Territoriais Na Fronteira: O Programa de Aceleração do Crescimento e as Transformações em Rondônia no Início do séc. XXI. 2012. 
Dissertação (Mestrado em Geografia Humana) - Universidade de São Paulo, São Paulo, 2012.

BRASIL. [Constituição (1988)]. Constituição da República Federativa do Brasil de 1988. Brasília, DF: Presidência da República, 1988. Disponível em:

http://www.cfess.org.br/pdf/legislacao_constituicao_federal.pdf. Acesso em: 23 abr. 2020.

BRASIL. Ministério da Defesa. Centro gestar e Operacional do Sistema de Proteçäo da Amazönia. Shapes de estradas do Estado de Rondônia - 2015. Disponível em: http://www.sipam.gov.br/assuntos/cartografia. Acesso em: 04 fev. 2020.

BRASIL. Ministério da Justiça e Segurança Pública. Fundaçäo Nacional do Índio. Terras Indígenas no Brasil ano 2020. Disponível em http://www.funai.gov.br/index.php/indios-nobrasil/terras-indigenas. Acesso em: 18 maio 2020.

BRASIL. Ministério da Justiça e Segurança Pública. Fundaçäo Nacional do Índio. Quadro de terras indígenas. Disponível em: http://www.funai.gov.br/index.php/indios-nobrasil/terras-indigenas. Acesso em: 09 dez. 2019.

BRASIL. Ministério da Justiça e Segurança Pública. Fundaçäo Nacional do Índio. Shape das terras indígenas de Rondônia - 2018. Disponível em:

http://www.funai.gov.br/index.php/shape. Acesso em: 04 fev. 2020.

HARVEY, David. Condição pós-moderna. São Paulo: Loyola, 1992.

HOBSBAWM, Eric. Karl Marx: formações econômicas pré-capitalista. São Paulo: Paz e Terra, 2006.

CASER, Artur Torres; SÁ, Dominichi Miranda de. O medo do sertão: a malária e a Comissão Rondon (1907-1915). História, Ciência, Saúde, Manguinhos, Rio de Janeiro, v. 18, n. 2, p. 471-497, 2011. Disponível em: http://www.scielo.br/pdf/hcsm/v18n2/10.pdf. Acesso em: 03 dez. 2019.

CASTRO, Sheila dos Santos; SILVA, Carlandio Alves. O agro é pop e não preserva ninguém: os discursos antagônicos de preservação ambiental. Revista Geographia Opportuno Tempore, Londrina, v. 6, n. 1, p. 93-108, 2020. Disponível em: http://www.uel.br/revistas/uel/index.php/Geographia/article/view/39658/27239. Acesso em: 23 abr. 2020.

COSTA SILVA, Ricardo Gilson. Dinâmicas territoriais em Rondônia: conflitos na produção e uso do território no período de 1970-2010. 2010. Tese (Doutorado em Geografia Humana) - Universidade de São Paulo, São Paulo, 2010.

COSTA SILVA, Ricardo Gilson; DANDOLINI, Gustavo. Conflitos agrários e acesso à terra em Rondônia. Revista Direito e Práxis, Rio de Janeiro, v. 9, n. 1, p. 461-479, 2018.

Disponível em: https://www.researchgate.net/publication/323997096. Acesso em: 23 abr. 2020.

COY, Martin. Desenvolvimento regional na periferia amazônica: organização do espaço, conflitos de interesses e programas de planejamento dentro de uma região de fronteira, o caso de Rondônia. Revista Núcleo de Altos Estudos da Amazônia - UFPA, Belém, p. 167-194, 1988. Disponível em: https://horizon.documentation.ird.fr/exldoc/pleins_textes/pleins_textes_7/b_fdi_03_01/37780.pdf. Acesso em: 04 maio 2016.

COY, Martin. Rondônia: Frente pioneira e Programa POLONOROESTE: O processo de Diferenciação Sócio Econômica na periferia e os limites do planejamento público. Revista Tübìnger Geographische Studien, Tubingen, n. 95, p. 253-270, 1987. Disponível em: https://horizon.documentation.ird.fr/exldoc/pleins_textes/pleins_textes_7/b_fdi_03_01/37780.pdf. Acesso em: 14 jan. 2014. 
DE PAULA, Jania Maria. Políticas públicas e as populações indígenas de Rondônia. Geografias, Belo Horizonte, n. 4, p. 71-80, 2008. Disponível em: https://periodicos.ufmg.br/index.php/geografias/article/view/13242. Acesso em: 15 abr. 2020.

DEMO, Pedro. Metodologia científica em ciências sociais. São Paulo: Atlas, 1992.

DOLLFUS, Olliver. O Espaço geográfico. Rio de Janeiro: Bertrand Brasil, 1991.

FERNANDES, Bernardo Mançano. Movimentos socioterritoriais e movimentos socioespaciais: contribuição teórica para uma leitura geográfica dos movimentos sociais. Observatorio Social de América Latina, Buenos Aires, n. 6, p. 271-283, 2005. Disponível em: http://bibliotecavirtual.clacso.org.ar/ar/libros/osal/osal16/D16MFernandes.pdf. Acesso em: 15 abr. 2020.

IBGE. Shape do Estado de Rondônia - 2019. Shape dos municípios de Rondônia 2019. Disponível em: https://portaldemapas.ibge.gov.br/portal.php\#mapa220344. Acesso em: 4 fev. 2020.

KÖCHE, José Carlos. Pesquisa científica: critérios epistemológicos. Petrópolis: Vozes, 2005.

LEFEBVRE, Henri. Marxismo: uma breve introdução. Porto Alegre: L\&PM, 2017.

MARTINS, José de Souza. A reinvenção da cidade na selva, Tempo Social. Revista de Sociologia da USP, São Paulo, n. 31, p. 11-33, 2019. Disponível em:

http://www.scielo.br/pdf/ts/v31n1/1809-4554-ts-31-01-0011.pdf. Acesso em: 15 abr. 2020.

MARTINS, Marseno Alvim. A Amazônia e nós. Rio de Janeiro: Biblioteca do Exército, 1971.

MOSER, Lilian Maria. Formação de capital social e o ideário do desenvolvimento sustentável no mundo rural rondoniense: a organização dos sistemas alternativos de produção dos produtores de Ouro Preto D'Oeste - RO. 2006. Tese (Doutorado em Desenvolvimento Sustentável) - Universidade Federal do Pará, Belém, 2006.

OTT, Ari Miguel Teixeira. Dos projetos de desenvolvimento, ao desenvolvimento dos projetos: o planafloro em Rondônia. 2002. Tese (Doutorado em Ciências Humanas) Universidade Federal de Santa Catarina, Florianópolis, 2002.

PEDLOWSKI, Marcos; DALE, Virginia; MATRICARDI, Eraldo. A criação de áreas protegidas e os limites da conservação ambiental em Rondônia. Revista Ambiente \& Sociedade, Campinas, n. 5, p. 93-108, 1999. Disponível em:

http://www.scielo.br/scielo.php?pid=S1414-

753X1999000200008\&script=sci_abstract\&tIng=pt. Acesso em: 14 abr. 2020.

POLITZER, Georges. Princípios elementares de filosofia. São Paulo: Hemus, 1975.

PORTO-GONÇALVES, Carlos Walter. A globalização da natureza e a natureza da globalização. Rio de Janeiro: Civilização Brasileira, 2011.

SANTOS, Gilberto Vieira. O movimento indígena contemporâneo no contexto dos conflitos no campo. Revista Terra Livre, São Paulo, n. 52, p. 323-359, 2019. Disponível em:

http://www.agb.org.br/publicacoes/index.php/terralivre/article/view/1520. Acesso em: 15 abr. 2020.

SANTOS, Alex Mota. Cartografias dos povos e das terras indígenas em Rondônia. Curitiba. 2014. Tese (Doutorado em Geografia) - Universidade Federal do Paraná, Curitiba, 2014.

SANTOS, Milton. A natureza do espaço: técnica e tempo: razão e emoção. São Paulo: Hucitec, 2012.

SANTOS, Milton. Por uma geografia nova: da crítica da geografia a uma geografia crítica. São Paulo: USP, 2004. 
SANTOS, Milton. Espaço e método. São Paulo: Nobel, 1997.

SANTOS, Vanubia Sampaio. O processo de ocupação de Rondônia e o impacto sobre as culturas indígenas. Revista Fórum Identidades, Itabaiana, n. 16, p. 197-220, 2014.

Disponível em: https://seer.ufs.br/index.php/forumidentidades/article/view/4267. Acesso em: 22 nov. 2019.

SILVA, Adnilson de Almeida. A questão indígena e os projetos de desenvolvimento na Amazônia ocidental. Revista Ciência Geográfica, Bauru, n. 16, p. 8-14, 2012. Disponível em:

http://www.agbbauru.org.br/publicacoes/revista/anoXVI_1/agb_xvi1_versao_internet/AGB_a br2012_02.pdf. Acesso em: 15 abr. 2020.

SILVA, Adnilson de Almeida. Impactos socioculturais em populações indígenas de Rondônia: estudo da nação Jupaú, Porto Velho. 2007. Dissertação (Mestrado em Geografia Humana) - Universidade Federal de Rondônia, Porto Velho, 2007.

Recebido: agosto de 2020.

Aceito: fevereiro de 2021. 